\title{
Clinical negligence: duty and breach
}

\author{
Chris Morris, ${ }^{1}$ Gautam Chawla' and Tania Francis*1
}

\section{Key points}

In order for a claimant to bring a successful clinical negligence claim they must show that the defendant owed them a duty of care, breached that duty, the breach caused some damage and that damage was reasonably foreseeable.

\begin{tabular}{l|l}
$\begin{array}{l}\text { Highlights that a defendant clinician will } \\
\text { always owe their patient a duty of care. }\end{array}$ & $\begin{array}{l}\text { Demonstrates that whether the court } \\
\text { will find that the clinician breached their } \\
\text { duty of care depends on factual and } \\
\text { expert evidence. }\end{array}$
\end{tabular}

Discusses case law which sets out the standard that a clinician is expected to meet when treating patients

\begin{abstract}
This article summarises the first two of the basic ingredients for a clinical negligence claim: duty of care and breach of duty. The article focuses on breach of duty and explores what evidence is required to prove breach, as well as some of the relevant legal case law.
\end{abstract}

\section{Introduction}

This is the first in a two-part series about clinical negligence, in which we will look at the essential components of a claim. In a nutshell, in order for a successful clinical negligence claim to be made, the claimant must show that the defendant healthcare practitioner/ provider:

- Owed them a duty of care

- Breached that duty

- The breach of duty caused the claimant some injury or damage

- That damage was foreseeable.

In this article we are going to look at the first two components: duty of care and breach of duty.

\section{Duty of care}

In most clinical negligence cases, there is no doubt that the defendant owed the claimant a duty of care. All healthcare practitioners know that they owe their patients a duty of

'Hempsons, London, UK

Correspondence to: Tania Francis

Email: t.francis@hempsons.co.uk

Refereed Paper.

Accepted 27 March 2019

DOI:10.1038/s41415-019-0312-9 care. Sometimes, it can be difficult to care for patients in the way we want to because of the systems in which we operate. The impact of those systems has always been recognised by those who have to work within their constraints, and their importance has been more widely recognised recently due to a number of high-profile cases. There are a few situations when the issue of whether a healthcare professional owes a claimant a duty of care can be less straightforward. These tend to occur when the claimant isn't the patient; for example, when the claimant is the spouse or parent of the patient.

\section{Breach of duty}

The issue of whether a healthcare practitioner breached their duty of care to their patient is central to clinical negligence claims, and it can be very difficult to determine. Sometimes, it's easy: if a rogue healthcare practitioner does something which no other practitioner would countenance, and which runs contrary to usual practice, guidance, and the evidence base, you don't need a lawyer or a judge to tell you that they have breached their duty of care. More usually, the point is highly contentious, and the difficulty is that there is often no right answer, until the judge makes a decision in court.

In most cases, going to court is not the best option, and therefore those of us who represent healthcare practitioners must do our best to advise our clients which way the dice will fall. This involves assessing the factual evidence. What happened? What did the healthcare practitioner do or say? Is there contemporaneous documentary evidence (usually in the form of the clinical records)? Or, as is often the case, are these records lacking in detail so that we are reliant on the patient's account of what happened, and the practitioner's recollection, if they have one. Often the consultation was unremarkable and several years ago, so that all the practitioner can tell us is what their usual practice is.

The next issue is that of expert evidence. Even if there is no dispute about what the healthcare practitioner did or didn't do, there may be a dispute about whether what they did was 'negligent'. That is, whether they breached their duty of care to the patient by treating them in the way that they did. This is where expert evidence comes in. The claimant will need expert evidence to support their claim and the defendant will similarly need expert evidence to defend the claim against them. In all but the most cut and dried cases, it will often be possible for both sides to find an expert who will support their case. The experts may be equally well qualified and experienced in their field, however ultimately it will be up to the judge on the day to decide which expert they consider is most persuasive. 
The case law in this area is ever-evolving. We start with Bolam (1957), ${ }^{1}$ which told us that if a healthcare practitioner acts in accordance with a responsible body of opinion, they are not negligent, even if others differ in opinion or practice. In Bolitho (1998), ${ }^{2}$ it was held that a judge will be entitled to choose between two bodies of expert opinion and to reject an opinion: which is logically indefensible. More recently we have Montgomery (2015), ${ }^{3}$ which applies to the tricky area of informed consent. In that case it was held that it is not enough to act in accordance with a reasonable body of opinion; the healthcare practitioner is under a duty to take reasonable care to ensure that the patient is aware of any material risks involved in any recommended treatment, and of any reasonable alternative or variant treatments. The test of materiality is whether, in the circumstances of the particular case, a reasonable person in the patient's position would be likely to attach significance to the risk; or the doctor is aware, or should reasonably be aware, that the particular patient would be likely to attach significance to it. It is therefore no longer enough to be able to prove that a responsible body of practitioners would not warn of a certain risk - if that risk is material to that specific patient, they must be warned of it, and to fail to do so is a breach of duty. This requires a fairly detailed knowledge of your patient and their circumstances, as well as time to explain the treatment options, including, crucially, the option of doing nothing or seeking treatment elsewhere, and the time to write it all down. It has been said that Montgomery is a case in which the courts caught up with what was already required of healthcare professionals by their regulatory bodies. Nevertheless, it is important when it comes to clinical negligence claims, as it places an additional burden on healthcare professionals defending such claims.

Another recent case of note is Darnley (2018), ${ }^{4}$ in which an NHS trust was held responsible for the information given to a patient by a receptionist about waiting times. The patient was told that there was a four to five hour wait to see a doctor, but not told that they would be seen by a triage nurse within half an hour. The patient left, not wanting to wait for hours, and sadly died. It was held that the trust had breached its duty of care to the patient by the receptionist giving inaccurate waiting time information. Again, this case places an additional burden on those defending themselves from clinical negligence claims. If you employ non-clinical staff, you must ensure that the information they provide to patients is accurate, as any failure in this regard risks a claim against you as their employer.

The courts do not expect all healthcare practitioners to meet the standards of the most experienced or skilful members of the profession, only of an ordinarily competent practitioner in that particular field. However, they will expect anyone who takes on specialist work to meet the standards of a specialist in that area. In addition, the degree to which account will be taken of a healthcare practitioner's relative inexperience is limited - the courts will expect a practitioner to meet the standards of a reasonably competent professional and will not make allowance for the fact that the practitioner may have only recently qualified, or may have limited experience of the particular procedure. The practitioner can, however, discharge their duty of care by seeking the assistance of a more senior or experienced colleague.

On the positive side, the courts do accept that things can go wrong without there having been any negligence on the part of the healthcare practitioner. The fact that there has been an untoward outcome does not necessarily mean that there has been negligence, and there can be no guarantee of a perfect result, although we often feel that this is precisely what patients expect.

\section{References}

1. Bolam v. Friern Hospital Management Committee [1957] 1 WLR 582.

2. Bolitho (Deceased) v. City and Hackney HA [1998] AC 232.

3. Montgomery v. Lanarkshire Health Board [2015] UKSC 11.

4. Darnley v. Croydon Health Services NHS Trust [2018] UKSC 50. 